\title{
Assessing Impact of BRRI Released Modern Rice Varieties Adoption on Farmers' Welfare in Bangladesh: Application of Panel Treatment Effect Model
}

\author{
M A Islam ${ }^{1 *}$, M C Rahman ${ }^{1}$, M A R Sarkar ${ }^{1}$ and M A B Siddique ${ }^{2}$
}

\begin{abstract}
This study assesses the impact of Bangladesh Rice Research Institute (BRRI) released modern wet (Aman) season rice variety adoption on farmers' well-being in Bangladesh. Bangladesh Integrated Household Survey (BIHS) data collected by IFPRI were used for this study. The study applied difference-in-difference treatment effect and difference-in-difference quantile treatment effect models using unbalanced panel data to achieve the set objectives. Analysis revealed that BRRI released wet (Aman) season rice technology has a robust and positive effect on small farmers' welfare in Bangladesh as indicated by the level of increases in per capita household real income, increases in real aman rice income, and also increases in yield and decreases both in poverty gap and squared poverty gap over time. The marginal and near landless farmers have not gained significantly through adopting BRRI released modern variety over non-adopters in terms of all the indicators except aman rice yield. However, only yield of BRRI released modern wet (Aman) season rice technology has positive and significant impact on the marginal and near landless farmers. As such, BRRI variety adoption seemed to be conducive in increasing the level of yield of marginal and near-landless farms but it hardly helps them to overcome the poverty level, unless other equity-enhancing policy measures are undertaken. Overall, there was large scope for enhancing adoption of BRRI released rice variety in order to reduce the poverty level in rural areas. The current rice policy (rice self-sufficiency) appears to be supportive to help Bangladesh rice sector for achieving food security in the country.
\end{abstract}

Key words: Adoption, Farmers' welfare, Treatment effect model, Poverty, Self-selection bias, quantile treatment effect model

\section{INTRODUCTION}

In Bangladesh, agriculture is the vital sector for attaining the development goals of alleviating poverty and increasing food security. Reducing poverty and improving food security through stimulating agricultural growth primarily depends on the adoption of modern agricultural technologies, including modern rice varieties (MVs). Rice is the main staple food grown in Bangladesh and is the vital crop for food security. Here, rice is grown throughout the year on high land to low land in three seasons. Modern varieties of rice were introduced in Bangladesh in the mid-sixties. In Bangladesh, BRRI was set up in 1970 to develop modern rice varieties better suited to local growing condition. The major achievements of rice research in Bangladesh as in other Asian countries, has been the development of high yielding modern varieties, i.e. seed based technologies. With the rapid development of local rice research capacity 100 high yielding rice varieties (including six hybrid rice) were developed during the last few decades (BRRI, 2019). Efforts were made to popularize those modern varieties among the farmers in different seasons.

The BRRI developed modern rice varieties (MVs) and technology packages played the key role in boosting annual rice production in Bangladesh from 9.93 million tons in 1972-73 to nearly 38.66 million tons annually in 2018-19 (MOA). The respectable growth in rice production was propelled by

\footnotetext{
${ }^{1}$ Senior Scientific Officer, Agricultural Economics Division, BRRI, ${ }^{2}$ Chief Scientific Officer, Agricultural Economics Division, BRRI, Gazipur 1701.*Corresponding author's e-mail address: arifagecon@gmail.com.
} 
adoption of high yielding modern rice varieties facilitated by an expansion of irrigation infrastructure. The adoption of modern rice seed technology has reached to nearly $87 \%$ of the total rice cropped area and rice production has increased more than three folds over the last four and half decades as a result of using high yielding modern rice varieties (BBS, 2019). The official statistics further indicate that, almost $91 \%$ of the total rice production in Bangladesh comes from high yielding modern rice varieties (MVs) (FPMU, 2019).

Available literature indicate that, modern rice varieties significantly contribute to improve farmers' well-being over traditional rice varieties (Hazell, 2010). In Bangladesh, modern rice technology developed by BRRI have been disseminated and profusely adopted by the farmers both in the dry (boro) and wet (aman) seasons over the last four and half decades. There is a large economic literature that investigate the effects of modern rice technology adoption on poverty alleviation and improvement in farmers' welfare (Bellon et al. 2006; Evenson and Gollin, 2003; Just and Zilberman, 1988). However, whether the dissemination of modern rice technology contributes to poverty reduction in rain-fed/Aman areas still remained controversial (Hazell, 2010). Given the complex causes underlying poverty and the diversity of livelihoods found among poor people, the relationship between agricultural research and poverty alleviation is necessarily perplexing (Hazell, 2010). There are a number of pathways through which Modern technologies could potentially benefit the poor farmers (Hazell and Haddad, 2001). In fact, gains from Modern agricultural technology have influenced the poor farmers directly by raising incomes of farming households and indirectly by raising employment and wage rates of functionally landless laborers and lowering the price of staple foods (Hossain et al. 1994; Winters et al. 1998; de Janvry and
Sadoulet, 1992; 2002). On the other hand, agricultural research could also work against the poor, since technologies are more suited to larger farms. Recent studies have highlighted that modern technologies have a positive impact on many small farmers, while the gains for the marginal farmers and landless agricultural laborers are too small to raise them above the poverty threshold (Islam, 2018; Hossain et al. 2007; Mendola, 2007 in Hazell, 2010). Notably, Pingali (2012) pointed out that petty farmers and landless agricultural laborers in South Asia might not be able to increase their welfare by adopting modern varieties (MVs) of rice, particularly in the rainy season, due to insecure ownership and tenancy rights, poorly developed input, credit, and output markets, and policies that discriminate against the poor.

A major difficulty in assessing the impact of a specific technology, such as Modern rice technology, requires establishing a suitable counterfactual against which the impact can be measured. The impact of Modern rice technology adoption must be separated from that of other socioeconomic factors that simultaneously determine the welfare of the households. Failure in doing so will cause the corresponding impact estimates to be biased (Wu et al. 2010 and Mendola, 2007). According to Angrist and Pischke (2009), instrumental variable (IV) based 2sls methodology is good, if the appropriate instruments can be applied. But it is very difficult to discover proper instruments to satisfy the assumptions of IV. Some studies have been conducted earlier to investigate the impact of agricultural technology on farmers' welfare in Asian and African countries using the propensity score matching (PSM) method based on cross sectional data (Mendola, 2007; Becerril and Abdulai, 2010; Khonje et al. 2015; Wu et al. 2010). However, Crost et al. (2007) measured the impact of agricultural technology on farmers' welfare using fixed effect models in India. The above mentioned studies did not 
consider the sample selection bias and the time invariant source of bias together. Unlike most of the previous studies, the present study is unique as it uses difference-in-difference with treatment effect model using unbalanced panel data to measure the impact of BRRI released modern rice technology in the wet (aman) season in rural Bangladesh. A combination of the PSM and DID estimators may overcome both the self-selection bias and time invariant source of bias problems. The DID with PSM estimators measure the impact of the 'treatment' with the difference between the adopters and the non-adopters of modern rice technology in the before-after periods difference in outcome variable.

Although there is little formal evidence to justify bootstrapping (Imbens, 2004), the approach has been widely applied. Specifically, kernel based matching with bootstrapping standard error gives better results (Abadie and Imbens, 2006; Rabalino and Pfaff, 2013). This study followed a bootstrapping methodology to calculate the corresponding standard error of the estimate of the technology impact.

Although Bangladesh has achieved remarkable progress in rice self-sufficiency, poverty is still a major problem. However, this study aims to investigate the heterogeneous impacts of BRRI released MV rice adoption during the rainy season on the welfare of the small, medium, and large farmers as well as to evaluate the current rice sector development policies in Bangladesh.

\section{METHODOLOGY}

\section{Data source}

For this study, two period panel data were obtained from the Bangladesh Integrated Household Survey (BIHS). The International Food Policy Research Institute (IFPRI) conducted two nationwide survey covering 6,500 nationally representative sample rural households in different divisions of Bangladesh during 2011/12 and 2015. Out of these 6,500 rural households, there are 1,542 wet (aman) season rice growing rural households in 2011/12 period and there are 1,522 wet (T. Aman) season rice growing households in 2015. The study did not consider 955 households in 2011/12 period and 935 households in 2015 those have adopted both modern and traditional rice varieties. Finally, 587 rural households (same for both periods) were selected on the basis of adoption and non-adoption of modern rice technology. This study used wet (T. Aman) season unbalanced panel data (because approximately $79 \%$ of same 1 and have been cultivated to follow-up period from the base period data) for DID-treatment effect model and quantile DID treatment effect model by using wet (T. Aman) season rice farming households' data of Bangladesh. In this study, real income was calculated using rural general consumer price index (CPI). All income data were converted to make equivalent to that of 2016-17 financial period for better understanding. Data modification and filtering were performed to ensure that the unit of measurement of each variable was consistent with the study objectives, and the quality of data were satisfactory. Although rice production in Bangladesh is carried out in three distinct seasons, this study used data of rice growing households only in the wet season, to achieve the set objectives.

\section{Analytical techniques}

i) DID treatment effect approach. According to Villa (2016), DID treatment effects approach ${ }^{1}$ is based on the existence of a pair of beforeand-after periods, namely, one baseline $(t=0)$ and one follow-up $(t=1)$. The basic DID framework is dependent on the availability of two groups of units $i$, including a treated

\footnotetext{
${ }^{1}$ DID treatment effect methodology has borrowed heavily from Villa (2016) article.
} 
group to which the treatment is delivered $\left(Z_{i}=\right.$ 1 ) and a control group to which the treatment is not delivered $\left(Z_{i}=0\right)$. The treatment indicator in the DID setting requires absence of any intervention in the baseline for either group $\left(D_{i, t=0}=0 \mid Z_{i}=1,0\right)$, and it requires the intervention to be positive for the treated group in the follow-up $\left(D_{i, t=1}=1 \mid Z_{i}=1\right)$. For a given outcome variable, $Y_{i t}$, the population DID treatment effect is given by the difference in the outcome variable for treated and control units before and after the intervention. The single DID setting is given by

$\mathrm{DID}=\left\{E\left(Y_{i t=1} \mid D_{i t=1}=1, Z_{i}=1\right)-E\left(Y_{i t=1} \mid D_{i t=1}=\right.\right.$ $0, \mathrm{Zi}=0)\}$

- $\left\{E\left(Y_{i t=0} \mid D_{i t=0}=0, Z_{i}=1\right)-E\left(Y_{i t=0} \mid D_{i t=0}=0, Z_{i}=\right.\right.$ 0)\}

This single DID can be combined with other non-experimental evaluation methods. Additional control covariates are important when observed heterogeneity may confound the identification strategy. Given the features of DID estimation, observed covariates should be exempted from the effects of the treatment. Thus, if observable covariates $\left(X_{i}\right)$ are available, they can be added into the analysis.

$\mathrm{DID}=\left\{E\left(Y_{i t=1} \mid D_{i t=1}=1, Z_{i}=1, X_{i}\right)-E\left(Y_{i t=1} \mid D_{i t=1}\right.\right.$ $\left.\left.=0, Z_{i}=0, X_{i}\right)\right\}$

- $\left\{E\left(Y_{i t=0} \mid D_{i t=0}=0, Z_{i}=1, X_{i}\right)-E\left(Y_{i t=0} \mid D_{i t=0}=\right.\right.$ $\left.\left.0, Z_{i}=0, X_{i}\right)\right\}$

A complementary method to the DID treatment effect is the incorporation of kernel propensity-score weights. Apart from the inclusion of control variables, observed covariates can be used to estimate the propensity score (the likelihood of being treated) and to calculate kernel weights following Heckman, Ichimura, and Todd (1997, 1998). Instead of accounting for control variables, this method matches treated and control units according to their propensity score. Each treated unit is matched to the whole sample of control units instead of on a limited number of nearest neighbors. To begin, one obtains the propensity score $\left(p_{i}\right)$ for both groups.

$p_{i}=E\left(Z_{i}=1 \mid X_{i}\right)$

According to Heckman, Ichimura, and Todd (1997), the kernel matching is given by the propensity score, given the covariates, which leads to the calculation of the kernel weights,

$$
w_{i}=\frac{K\left(\frac{p_{i}-p_{k}}{h_{n}}\right)}{\sum K\left(\frac{p_{i}-p_{k}}{h_{n}}\right)} \ldots
$$

in which $\mathrm{K}(\cdot)$ is the kernel function and $h_{n}$ is the selected bandwidth. The kernel weights are then introduced into (1) to obtain a kernel propensity-score matching DID treatment effect as follows:

$\mathrm{DID}=\left\{E\left(Y_{i t=1} \mid D_{i t=1}=1, Z_{i}=1\right)-w_{i} \times\right.$ $\left.E\left(Y_{i t=1} \mid D_{i t=1}=0, Z_{i}=0\right)\right\}$

- $\left\{E\left(Y_{i t=0} \mid D_{i t=0}=0, Z_{i}=1\right)-w_{i} \times E\left(Y_{i t=0} \mid D_{i t=0}=\right.\right.$ $\left.\left.0, Z_{i}=0\right)\right\}$

Now, to increase the internal validity of the DID estimand, one can restrict (4) to the common support of the propensity score for treated and control groups. The common support is the overlapping region of the propensity for treated and control groups. This sample of $\mathrm{i}$ units can be restricted to the region defined as

(i: $p_{i} \in\left[\max \left\{\min \left(p_{i} \mid Z_{i}=1\right), \quad \min \left(p_{i} \mid Z_{i}=0\right)\right\}\right.$, $\left.\left.\min \left\{\max \left(p_{i} \mid Z_{i}=1\right), \min \left(p_{i} \mid Z_{i}=0\right)\right\}\right]\right)$

Complementarily, when treated and control units cannot be followed over the baseline and follow-up periods, the DID treatment effects can be estimated with repeated cross-sections. This is very common when a treatment has been administered to certain regional or demographic groups over several cross-sections. The kernel propensity score matching with repeated cross-section DID treatment effects is specified following Blundell and Dias (2009).

$\mathrm{DID}=\left\{E(Y i t=1 \mid\right.$ Dit=1 $=1, Z i=1)-w_{i t=1}^{c} \times$ $\left.E\left(Y_{i t=1} \mid D_{i t=1}=0, Z_{i}=0\right)\right\}$

- $w_{i t=0}^{t} \times\left\{E\left(Y_{i t=0} \mid D_{i t=0}=0, Z_{i}=1\right)-w_{i t=0}^{c} \times\right.$ $\left.E\left(Y_{i t=0} \mid D_{i t=0}=0, Z_{i}=0\right)\right\}$

Here $w_{i t=0}^{c}$ and $w_{i t=1}^{c}$ are the kernel weights for the control group in the baseline 
and follow-up periods, respectively, while $w_{i t=0}^{t}$ is the kernel weight for the treated groupin the baseline period. The three sets of kernel weights are calculated independently according to the estimated propensity score and do not require the panel structure ofthe units in the sample.

Finally, the balancing property of the treated and the control can be tested. Given the availability of observable covariates, it can be shown that in absence of the treatment, the outcome variable is orthogonal to the treatment indicator given the set of covariates. In other words, the balancing property can be tested in the baseline as

$Y_{i t=0} \perp Z_{i} \mid X$

Note that the balancing property is optional in the DID setting. The most important assumption, which is not tested in this approach, is the complement of the parallel paths of the outcome for the treated and the control groups. Given the availability of two periods in this analysis, this assumption cannot be tested here. For an extension of this test, see Mora and Reggio (2012).

DID quantile treatment effect approach. Ninety-five percent of applied econometrics is concerned with mean effects, yet distributional effects are no less important. The distribution of the dependent variable may change in many ways that are not revealed or are only incompletely revealed by an examination of averages. For example, the income distribution can become more compressed or the upper-tail inequality may increase while the lower-tail inequality decreases. Therefore, applied economists and policy makers are increasingly interested in distributional effects. The estimation of quantile treatment effects (QTEs) is a powerful and intuitive tool that allows us to discover the effects on the entire distribution. As an alternative motivation, median regression is often preferred to mean regression to reduce susceptibility to outliers.

We consider the effect of a binary treatment variable $D$ on a continuous outcome variable
$Y$. Let $Y_{i}^{1}$ and $Y_{i}^{0}$ be the potential outcomes of individual $i$. Hence, $Y_{i}^{1}$ would be realized if individual $i$ were to receive treatment 1 , and $Y_{i}^{0}$ would be realized otherwise. $Y_{i}$ is the observed outcome, which is $Y_{i} \equiv Y_{i}^{1} D_{i}+Y_{i}^{0}$ (1$\left.D_{i}\right)$. In this study, we identify and estimate the entire distribution functions of $Y^{1}$ and $Y^{0}$. Because QTEs are an intuitive way to summarize the distributional impact of a treatment, we focus our attention especially on them. We often observe not only the outcome and the treatment variables but also some characteristics $X$ (independent variables). We can therefore either define the QTEs conditionally on the covariates or unconditionally. In addition, we have to deal with selection on unobservables. Finally, we used this concept to DID kernel framework. See Angrist and Pischke (2009) for detailed information on quantile treatment effects and Meyer, Viscusi, and Durbin (1995) for an illustrative example.

Estimation procedure. To obtain the expected estimates for the specified model equation (1), we rely on linear regression for the single DID analysis. The subsequent complementary introduction of control variables or kernelpropensity-score matching weights is similarly specified by linear regression. In thebasic framework, the estimation can be shown as follows:

Outcome_var $=$

$\beta_{0}+\beta_{1} \times$ period ()$_{i}+\beta_{2} \times$ treated ()$_{i}+\beta_{3} \times$ period ()$_{i} \times$ treated ()$_{i}+e_{i}$

Here outcome_var $i$ is the outcome variable for each unit; period ()$_{i}$ is a binary variable taking the value of 0 in the baseline and 1 in the follow-up periods; and treated() $)_{I}$ is a binary variable indicating the treatment status for each unit, similar to $Z_{i}=1$.

The expected values in (1) are obtained from the interaction of the estimated coefficients. The estimated coefficients have the following interpretation:

- $\widehat{\beta_{0}}$ : the mean outcome of the control group at the baseline. 
- $\widehat{\beta_{0}}+\widehat{\beta_{1}}$ : the mean outcome of the control group in the follow-up.

- $\widehat{\beta_{2}}$ : the single difference between the treated and the control groups at the baseline.

- $\widehat{\beta_{0}}+\widehat{\beta_{2}}$ : the mean outcome of the treated group at the baseline.

- $\widehat{\beta_{0}}+\widehat{\beta_{1}}+\widehat{\beta_{2}}+\widehat{\beta_{3}}$ : the mean outcome of the treated group in the follow-up.

- $\widehat{\beta_{3}}$ : the DID estimation.

Measuring Poverty. In the context of measuring poverty in a population the indices in Foster et al. (1984) are commonly used which is expressed as:

$P_{\propto}=\frac{1}{N} \sum_{i=1}^{N}\left[\frac{Z-y_{i}}{Z}\right]^{\propto}(\alpha>0)$ and $\left(y_{i}<Z\right) \ldots \ldots .(6)$ where $Z$ is the agreed-upon poverty line (US\$ $1.25 /$ capita/day) converted to Bangladeshi Taka, $N$ is the total household population, $y_{i}$ is household income per capita for the $\mathrm{i}^{\text {th }}$ person, and $\propto$ is a poverty aversion (sensitivity) parameter. When $\propto=1$, it is a measure of the poverty gap. When $\propto=2, P$ equals the squared poverty gap, which is used as a measure of the severity of poverty. The study used the international poverty line of US\$ 1.25/capita/day for round 1 (2011-12: base period) and US\$ 1.90/capita/day (adjusted from US\$1.25) (WBG, 2016) for round 2, which is converted to taka per capita per year using official exchange rate.

\section{RESULTS AND DISCUSSION}

\section{Level of MV rice adoption in two different periods}

Data in Table 1 represent the level of rice technology adoption by farm size categories over time. In the base period (2011/12), adoption of BRRI released MV rice varieties by marginal and near landless farms was higher $(76.03 \%)$ compared to that of medium and large farms $(74.51 \%)$ and small farms $(70.77 \%)$, respectively. However, in the follow-up period (2015), adoption of MVs showed a reverse situation for the case of medium and large farms. In case of marginal and near landless farms and small farms, the level of area devotion to modern rice (MVs) adoption increased at a higher rate compared to that for local rice varieties $(\mathrm{LV})$ in wet season over time.

The data in Table 2 depict the level of differences in yield and other relevant economic parameters of the sample farms in the study areas. The result indicates that there is a difference between the yield of adopters and non-adopters within four years. As for the welfare impact of modern rice technology, a straightforward comparison between both per capita total household real income of adopters and non-adopters was considered. While per capita total household real income indicates the ability of the household to purchase its basic needs of life, and thus it provides information on the food security status of households. The result indicates that there is a difference between the per capita total household real income of adopters and nonadopters over time. The mean differences in per capita real income from rice production in the wet (T. Aman) season, and wet season rice yield (kg/ha) of adopters and non-adopters indicates that adopters of Modern rice technology are better off than non-adopters over time.

As evident in Table 2, the incidence of poverty was lower among adopters (35.02\%) than non-adopters $(39.56 \%)$ in the base period. On the other hand, incidence of poverty decreased in case of adopters (25.34\%) than non-adopter $(33.32 \%)$ in the follow-up period. The level of poverty in case of adopters decreasing more compared to that of nonadopter over the periods. The depth of poverty was lower among adopters (14.87\%) than nonadopters $(20.59 \%)$ in the base period. On the other hand, depth of poverty decreased in the case of adopters (8.46\%) than non-adopter $(15.69 \%)$ in the follow-up period, and the trend or rate in decrease of poverty was higher in case of the MV adopters. In addition, severity 
of poverty was also lower (7.51\%) among adopters as compared to the non-adopters $(11.24 \%)$ in the base period. Similarly, the severity of poverty was also lower (4.42\%) among adopters as compared to the nonadopters $(8.71 \%)$ in the follow-up period.

Based on the availability of unbalanced panel data, the welfare impact of the adoption of modern rice technology (BRRI varieties) in wet season on comparatively resource-poor rural households were assessed. Specifically, the focus was on the underlying causal effect of 'direct' impact of modern rice technology adoption. For measuring the impact of modern rice technology adoption on household welfare, the DID treatment effect model (DID-
PSM) was employed. Quantile DID treatment effects model was also used for the estimation at specified quantile like $0.25,0.50$ and 0.75 .

The study did not employ DID-PSM model in case of large and medium farms, since in this case the sample size was small. For the small farms, causal effect of wet season BRRI developed modern rice technology adoption on per capita household annual real income (tk/year) appeared positive and statistically significant. The increase in real income by the MV adopting farms was $67.80 \%$ higher than the non-adopters over the period (Table 3). Furthermore, wet (T. Aman) season per capita real rice income (tk/year) was positive and statistically significant and the

Table 1. Rice technology adoption by farm size categories in wet (T. Aman) season in Bangladesh.

\begin{tabular}{|c|c|c|c|c|c|c|}
\hline \multirow[t]{2}{*}{ Farm categories } & \multicolumn{3}{|c|}{ 2011/12 (base period) } & \multicolumn{3}{|c|}{2015 (follow-up period) } \\
\hline & BRRI MVs & LVs & Total & BRRI MVs & LVs & Total \\
\hline $\begin{array}{l}\text { Marginal and near landless farms }(<0.21 \text { ha) (no.) } \\
\text { (\% of farms) }\end{array}$ & $\begin{array}{c}111 \\
(76.03)\end{array}$ & $\begin{array}{c}35 \\
(23.97)\end{array}$ & $\begin{array}{c}146 \\
(100)\end{array}$ & $\begin{array}{c}97 \\
(80.17)\end{array}$ & $\begin{array}{c}24 \\
(19.83)\end{array}$ & $\begin{array}{l}121 \\
(100)\end{array}$ \\
\hline $\begin{array}{l}\text { Small farms }(0.21 \text { ha }-1.01 \text { ha }) \text { (no.) } \\
((\% \text { of farms })\end{array}$ & $\begin{array}{c}276 \\
(70.77)\end{array}$ & $\begin{array}{c}114 \\
(29.23)\end{array}$ & $\begin{array}{l}390 \\
(100)\end{array}$ & $\begin{array}{c}320 \\
(78.04)\end{array}$ & $\begin{array}{c}90 \\
(21.96)\end{array}$ & $\begin{array}{l}410 \\
(100)\end{array}$ \\
\hline $\begin{array}{l}\left.\text { Medium and large farms }{ }^{1}>1.01 \text { ha }\right) \text { (no.) } \\
\text { (\% of farms) }\end{array}$ & $\begin{array}{c}38 \\
(74.51)\end{array}$ & $\begin{array}{c}13 \\
(25.49)\end{array}$ & $\begin{array}{c}51 \\
(100)\end{array}$ & $\begin{array}{c}35 \\
(62.50)\end{array}$ & $\begin{array}{c}21 \\
(37.50)\end{array}$ & $\begin{array}{c}56 \\
(100)\end{array}$ \\
\hline $\begin{array}{l}\text { Total farms (no.) } \\
\text { (\% of farms) }\end{array}$ & $\begin{array}{c}425 \\
(72.40)\end{array}$ & $\begin{array}{c}162 \\
(27.60)\end{array}$ & $\begin{array}{c}587 \\
(100)\end{array}$ & $\begin{array}{c}452 \\
(77.00)\end{array}$ & $\begin{array}{c}135 \\
(23.00)\end{array}$ & $\begin{array}{l}587 \\
(100)\end{array}$ \\
\hline
\end{tabular}

Note: ${ }^{1)}$ Due to few sample large farms (2 for 2011-12 and 5 for 2015), they are included in the same category as medium farms.

Table 2. Differences in wet season rice yield and other economic parameters of the sample households by adoption category in two periods.

\begin{tabular}{|c|c|c|c|c|c|c|}
\hline \multirow[t]{2}{*}{ Items } & \multicolumn{3}{|c|}{ 2011-12 (base period) } & \multicolumn{3}{|c|}{2015 (follow up period) } \\
\hline & Adopter & $\begin{array}{c}\text { Non- } \\
\text { adopter }\end{array}$ & T-test & Adopter & $\begin{array}{c}\text { Non- } \\
\text { adopter }\end{array}$ & T-test \\
\hline Rice yield (t/ha) & 3180.27 & 1969.13 & $1211.14^{* *}$ & 3959.92 & 2243.03 & $1716.89^{* * *}$ \\
\hline $\begin{array}{l}\text { Per capita wet (aman) } \\
\text { season real income }(\mathrm{tk} / \text { year) }\end{array}$ & 7501.51 & 5536.66 & $1964.85^{* *}$ & 7166.43 & 3520.28 & $3646.15^{* * *}$ \\
\hline $\begin{array}{l}\text { Per capita household } \\
\text { real income (tk/year) }\end{array}$ & 92737.04 & 85099.87 & $7637.17^{* *}$ & 107871.8 & 76148.69 & $31723.11^{* * *}$ \\
\hline Head count ratio (HCR) (\%) & 35.02 & 39.56 & $4.54^{* *}$ & 25.34 & 33.32 & $7.98^{* * *}$ \\
\hline Poverty gap index (PGI) (\%) & 14.87 & 20.59 & $5.72^{* *}$ & 8.46 & 15.69 & $7.23^{* * *}$ \\
\hline $\begin{array}{l}\text { Squared poverty gap index } \\
\text { (SPGI) }(\%)\end{array}$ & 7.51 & 11.24 & $3.73^{*}$ & 4.42 & 8.71 & $4.29^{* *}$ \\
\hline Sample size & 425 & 162 & - & 452 & 135 & - \\
\hline
\end{tabular}

Note: Real income based calculation (using rural general consumer price index (CPI): base year 2016-17)

Data source: IFPRI, BIHS: 2011-12 and BIHS: 2015 data.

Official exchange rate:2016-17: US\$ 1= 79.1192 Bangladeshi Taka.

${ }^{* * *} \mathrm{p}<0.01,{ }^{* *} \mathrm{p}<0.05,{ }^{*} \mathrm{p}<0.10$ 
effect of adopting MV rice was $88.50 \%$ higher than non-adopters over the period. The results further imply that, difference in rice yield in wet season was statistically significant and the effect of adopting BRRI MVs was 30.10\% higher than non-adopter over the years. Moreover, poverty gap index and squared poverty gap index appeared positive and statistically significant. The decrease in poverty gap index and squared poverty gap index by the MV adopting farms was $12.90 \%$ and $6.10 \%$, higher respectively than the nonadopter over the period. However, per capita household real income, wet (T. Aman) season per capita real rice income, and yield obtained by the MV adopters under DID-kernel $1^{\text {st }}, 2^{\text {nd }}$ and $3^{\text {rd }}$ quantile farmers have increased significantly compared to that of non-adopter over the period (Table 3).

On the contrary, marginal and near landless farmers did not gain significantly through adopting BRRI released wet ( $\mathrm{T}$. Aman) season rice technology vis-à-vis nonadopter for the case of per capita real income, and wet season real rice income, poverty gap index and squared poverty gap index over time (Table 4). However, on average, difference of yield of rice $(\mathrm{kg} / \mathrm{ha})$ in wet season was positive and statistically significant and effect of adopting BRRI MVs was $18.5 \%$ higher than non-adopter over the period. It implies that dissemination of new rice technology contributes to food availability though it does not impact on the welfare of the marginal and near landless farmers (Table 4). However, per capita household real income, wet ( $T$. Aman) season per capita real rice income, and yield obtained by the MV adopters under DID-kernel $1^{\text {st }}, 2^{\text {nd }}$ and $3^{\text {rd }}$ quantile farmers did not increase significantly compared to that of non-adopter (Table 4).

Thus, DID treatment effect model estimates indicate that wet season BRRI MV rice technology adoption has a positive and robust impact on household welfare in terms of per capita household annual real income, wet season per capita real rice income, as well as wet season rice yield in Bangladesh. In addition, there has been a trend towards decreasing poverty over the periods of 2011-12 to 2015 in Bangladesh.

Table 3. Results of DID treatment effect analysis for BRRI released modern rice growing households in the wet (Aman) season in Bangladesh (Small farm size)

\begin{tabular}{|c|c|c|c|c|}
\hline \multirow[b]{2}{*}{ Indicator } & \multirow[b]{2}{*}{$\begin{array}{c}\text { DID Kernel } \\
(b w=0.03)\end{array}$} & \multicolumn{3}{|c|}{ Quantile regression } \\
\hline & & $\begin{array}{c}\text { DID Kernel } \\
(\mathrm{bw}=0.03) \\
\text { Quantile }(0.25)\end{array}$ & $\begin{array}{c}\text { DID Kernel } \\
\text { (bw }=0.03) \\
\text { Quantile }(0.50)\end{array}$ & $\begin{array}{c}\text { DID Kernel } \\
\text { (bw }=0.03) \\
\text { Quantile }(0.75)\end{array}$ \\
\hline Ln rice yield $\left(\mathrm{t} \mathrm{ha}^{-1}\right)$ & $\begin{array}{l}30.10^{* *} \\
(0.130)\end{array}$ & $\begin{array}{l}15.0^{\star *} \\
(0.071)\end{array}$ & $\begin{array}{l}20.30^{* *} \\
(0.081)\end{array}$ & $\begin{array}{l}13.81^{* *} \\
(0.064)\end{array}$ \\
\hline $\begin{array}{l}\text { Ln per capita wet (Aman) season real } \\
\text { income (Tk/year) }\end{array}$ & $\begin{array}{l}88.50^{* *} \\
(0.359)\end{array}$ & $\begin{array}{c}106.80^{* * *} \\
(0.194)\end{array}$ & $\begin{array}{c}129.50^{* * *} \\
(0.186)\end{array}$ & $\begin{array}{l}94.70^{* * * *} \\
(0.450)\end{array}$ \\
\hline $\begin{array}{l}\text { Ln per capita household real income } \\
\text { (Tk/year) }\end{array}$ & $\begin{array}{l}67.80^{* * *} \\
(0.188)\end{array}$ & $\begin{array}{l}41.60^{* * *} \\
(0.124)\end{array}$ & $\begin{array}{c}38.10^{* * *} \\
(0.114)\end{array}$ & $\begin{array}{l}46.90^{* * *} \\
(0.133)\end{array}$ \\
\hline Poverty gap index (PGI) $(\%)$ & $\begin{array}{l}-12.90^{* *} \\
(0.071)\end{array}$ & - & - & - \\
\hline Square poverty gap index (SPGI) (\%) & $\begin{array}{l}-6.1^{*} \\
(0.036)\end{array}$ & - & - & - \\
\hline Balancing property satisfied & yes & yes & yes & yes \\
\hline Common support imposed & yes & yes & yes & yes \\
\hline Sample size & 410 & 410 & 410 & 410 \\
\hline
\end{tabular}

Note: 1) Parentheses indicate bootstrap standard error with 100 replications.

2) ${ }^{* * *} \mathrm{p}<0.01,{ }^{* *} \mathrm{p}<0.05,{ }^{*} \mathrm{p}<0.10$. 
Table 4. Results of DID treatment effect analysis for BRRI released modern rice growing households in the wet (aman) season in Bangladesh (Marginal and near to landless farm size)

\begin{tabular}{|c|c|c|c|c|}
\hline \multirow[b]{2}{*}{ Indicators } & \multirow[b]{2}{*}{$\begin{array}{c}\text { DID Kernel } \\
\left(b_{w}=0.03\right)\end{array}$} & \multicolumn{3}{|c|}{ Quantile regression } \\
\hline & & $\begin{array}{c}\text { DID Kernel } \\
(\mathrm{bw}=0.03) \\
\text { Quantile }(0.25) \\
\end{array}$ & $\begin{array}{c}\text { DID Kernel } \\
(b w=0.03) \\
\text { Quantile }(0.50) \\
\end{array}$ & $\begin{array}{c}\text { DID Kernel } \\
(b w=0.03) \\
\text { Quantile }(0.75)\end{array}$ \\
\hline Ln rice yield (t/ha) & $\begin{array}{c}18.5^{\star} \\
(0.105)\end{array}$ & $\begin{array}{l}14.39^{*} \\
(0.077)\end{array}$ & $\begin{array}{l}16.70^{* *} \\
(0.071)\end{array}$ & $\begin{array}{l}15.3^{* *} \\
(0.061)\end{array}$ \\
\hline $\begin{array}{l}\text { Ln per capita wet season real income } \\
\text { (tk/year) }\end{array}$ & $\begin{array}{l}49.60^{\mathrm{NS}} \\
(0.585)\end{array}$ & $\begin{array}{l}70.90^{\mathrm{NS}} \\
(0.669)\end{array}$ & $\begin{array}{r}98.40^{\mathrm{NS}} \\
(0.605)\end{array}$ & $\begin{array}{l}85.10^{\mathrm{NS}} \\
(0.802)\end{array}$ \\
\hline $\begin{array}{l}\text { Ln per capita household real income } \\
\text { (tk/year) }\end{array}$ & $\begin{array}{l}45.00^{\mathrm{NS}} \\
(0.390)\end{array}$ & $\begin{array}{l}21.0^{\mathrm{NS}} \\
(0.453)\end{array}$ & $\begin{array}{l}14.6^{\mathrm{NS}} \\
(0.246)\end{array}$ & $\begin{array}{l}37.01^{\mathrm{NS}} \\
(0.235)\end{array}$ \\
\hline Poverty gap index (PGI) $(\%)$ & $\begin{array}{l}-21.2^{\mathrm{NS}} \\
(0.201)\end{array}$ & - & - & - \\
\hline Square poverty gap index (SPGI) (\%) & $\begin{array}{l}-12.7^{\mathrm{NS}} \\
(0.108)\end{array}$ & - & - & - \\
\hline Balancing property satisfied & yes & yes & yes & yes \\
\hline Common support imposed & yes & yes & yes & yes \\
\hline Sample size & 146 & 146 & 146 & 146 \\
\hline
\end{tabular}

Note: 1) Parentheses indicate bootstrap standard error with 100 replications.

2) ${ }^{* * *} \mathrm{p}<0.01,{ }^{* *} \mathrm{p}<0.05,{ }^{*} \mathrm{p}<0.10$. NS $=$ Not significant

Table 5. Results of DID treatment effect analysis for BRRI released modern rice growing households in the wet (aman) season in Bangladesh (Pool farm size)

\begin{tabular}{|c|c|c|c|c|}
\hline \multirow[b]{2}{*}{ Indicators } & \multirow[b]{2}{*}{$\begin{array}{l}\text { DID Kernel } \\
(b w=0.03)\end{array}$} & \multicolumn{3}{|c|}{ Quantile regression } \\
\hline & & $\begin{array}{c}\text { DID Kernel } \\
(\mathrm{bw}=0.03) \\
\text { Quantile(0.25) }\end{array}$ & $\begin{array}{l}\text { DID Kernel }(\mathrm{bw}=0.03) \\
\text { Quantile }(0.50)\end{array}$ & $\begin{array}{c}\text { DID Kernel }(b w=0.03) \\
\text { Quantile }(0.75)\end{array}$ \\
\hline Ln rice yield $\left(\mathrm{t} \mathrm{ha}^{-1}\right)$ & $\begin{array}{l}25.4^{* *} \\
(0.117)\end{array}$ & $\begin{array}{c}11.0^{* *} \\
(0.053)\end{array}$ & $\begin{array}{l}19.4^{* * *} \\
(0.063)\end{array}$ & $\begin{array}{l}11.8^{* *} \\
(0.053)\end{array}$ \\
\hline $\begin{array}{l}\text { Ln per capita wet } \\
\text { season real income } \\
\text { (tk/year) }\end{array}$ & $\begin{array}{l}82.2^{* *} \\
(0.326)\end{array}$ & $\begin{array}{l}99.3^{* * *} \\
(0.184)\end{array}$ & $\begin{array}{c}132.5^{* * *} \\
(0.228)\end{array}$ & $\begin{array}{l}33.6^{\mathrm{NS}} \\
(0.306)\end{array}$ \\
\hline $\begin{array}{l}\text { Ln per capita } \\
\text { household real income } \\
\text { (tk/year) }\end{array}$ & $\begin{array}{l}48.8^{* * *} \\
(0.133)\end{array}$ & $\begin{array}{l}22.8^{* *} \\
(0.095)\end{array}$ & $\begin{array}{l}28.2^{* * *} \\
(0.084)\end{array}$ & $\begin{array}{l}36.1^{* * *} \\
(0.083)\end{array}$ \\
\hline $\begin{array}{l}\text { Poverty gap index } \\
\text { (PGI) }(\%)\end{array}$ & $\begin{array}{c}-14.4^{* * *} \\
(0.058)\end{array}$ & - & - & - \\
\hline $\begin{array}{l}\text { Square poverty gap } \\
\text { index (SPGI) }(\%)\end{array}$ & $\begin{array}{l}-6.2^{* *} \\
(0.030)\end{array}$ & - & - & - \\
\hline $\begin{array}{l}\text { Balancing property } \\
\text { satisfied }\end{array}$ & yes & yes & yes & yes \\
\hline $\begin{array}{l}\text { Common support } \\
\text { imposed }\end{array}$ & yes & yes & yes & yes \\
\hline Sample size & 587 & 587 & 587 & 587 \\
\hline
\end{tabular}

Note: 1) Parentheses indicate bootstrap standard error with 100 replications.

2) ${ }^{* * *} \mathrm{p}<0.01,{ }^{* *} \mathrm{p}<0.05$ 
CONCLUSION AND POLICY RECOMMENDATIONS

Findings of the study revealed that BRRI released wet (aman) season rice technology has a robust and positive effect on small farmers' welfare in Bangladesh as measured by the level of increases in per capita household real income, increases in wet (aman) season real rice income, and also increases in wet season rice yield, and decreases both poverty gap and squared poverty gap over time.

On the other hand, the marginal and near landless farmers have not gained significantly through adopting BRRI released modern rice technology over non-adopter in terms of all the indicators except rice yield. However, difference of yield of rice was positive and statistically significant and effect of adopting BRRI MVs was $18.5 \%$ higher than non-adopter over the period. Therefore, BRRI rice technology adoption seems to be conducive in increasing the level of yield of marginal and near-landless farms but it hardly helps them to overcome the poverty line, unless other equityenhancing policy measures are undertaken.

Overall, there is large scope for the enhanced adoption of BRRI released rice technology in order to reduce the level of poverty in rural areas. It is necessary to develop rice technology targeting to increase the level of income as well as reduce the poverty of the resource poor marginal and near landless farmers. Furthermore, the government policy makers, and rice breeders should emphasize not only on the development of stress tolerant rice varieties for addressing the climate change situation but also to take into consideration of different stress prone areas under rice cultivation. Moreover, the government policy makers should further emphasize on the creation of employment opportunity (i.e., expansion of readymade garments industries, cottage industries, jute industries, rural processing and manufacturing industries, handloom industries, transport operations, reconstruction and expansion of roads and highways, construction of different infrastructures, and post-harvest processing industries) for the surplus agricultural workers in non-agricultural sector for improving the welfare of the poorest group of farmers. However, the government should focus on the diversification of agricultural production systems in the dry season (introduce new cropping patterns) to increase the annual income and reduce the poverty of the poor farmers. Therefore, the current rice policy might be supported to help to Bangladeshi rice sector for achieving food security in Bangladesh. Thus it (rice self-sufficiency) appears to be supportive to help Bangladeshi rice sector for achieving food security in the country using BRRI released modern seed technology.

\section{REFERENCES}

Abadie, A, and D W Imbens. 2006. "On the Failure of the Bootstrap for Matching Estimators." NBER Technical Working Paper 325. Cambridge, MA: National Bureau of Economic Research. Available at www.nber.org/ papers/t0325.pdf

Angrist, J D and J S Pischke. 2009. Mostly harmless econometrics an empiricist's companion. Princeton University Press, Princeton, New Jersey.

Becerril, J and A Abdulai. 2010. "The impact of Modern maize varieties on poverty in Mexico: A propensity score-matching approach." World Development, 38(7):1024-1035.

BER. 2019. Bangladesh Economic Review, Ministry of Finance, Govt. of the Peoples Republic of Bangladesh, Dhaka, Bangladesh.

BRRI. 2019. Modern Rice Cultivation (Bengali : Adhunik Dhaner Chas), Bangladesh Rice Research Institute (BRRI), Gazipur-1701, Bangladesh. http:/ / www.brri.gov.bd/site/page/6952c1d9af2c-404c-a2e7-f7eb5c1cae92/-, 2019-07-28.

Bellon, M R, M Adato, J Becerril, and D Mindek. 2006. "Poor farmers perceived benefits from different types of maize germplasm: The Case of Creolization in Lowland Tropical Mexico", World Development, 34(1): 113-129.

Blundell, R, and M C Dias. 2009. Alternative approaches to evaluation in empirical microeconomics. Journal of Human Resources, 44: 565-640.

Crost, B, B Shankar, R Bennett, and S Morse .2007. “Bias from farmer self-selection in genetically modified crop productivity estimates: Evidence from Indian data." Journal of Agricultural Economics, 58(1):24-36. 
De Janvry, A, E Sadoulet. 1992. "Agricultural trade liberalisations and low income countries: a general equilibrium-multimarket approach." American Journal of Agricultural Economics,74(2): 268-280.

De Janvry A, E Sadoulet. 2002. 'World poverty and the role of agricultural technology: direct and indirect effects.' Journal of Development Studies, 38(4): 126.

Evenson, R, and D Gollin . 2003. 'Assessing the impact of the green revolution: 1960 to 2000', Science, 300(2):758-762.

Foster, J, J Greer and E Thorbecke. 1984. 'A class of decomposable poverty measures.' Econometrica, 81(2):761-766.

FPMU. 2019. Database on food situation, Bangladesh. Ministry of Food, Government of the People's Republic of Bangladesh, Dhaka, Bangladesh.

Freebairn, D K . 1995. Did the green revolution concentrate incomes? A quantitative study of research reports. World Development, 23(2): 265-279.

Hazell, P B R. 2010. An assessment of the impact of agricultural research in South Asia Since the green revolution, Hand Book of Agricultural Economics, Elsevier, Vol.4: 3469-3530, http:/ / dx.doi.org/10.1016/S15740072(09)04068-7.

Hazell, P, and L Haddad. 2001. Agricultural research and poverty reduction. Food, Agriculture, and the Environment, Discussion Paper 34. International Food Policy Research Institute, Washington, DC: USA.

Heckman, J J, H I chimura and P E Todd. 1997. “Matching as an econometric evaluation estimator: Evidence from evaluating a job training programme." Review of Economic Studies, 64:605654.

Heckman, J, H I chimura, J Smith and P E Todd. 1998. 'Characterizing selection bias using experimental data.' Econometrica, 66: 1017-98.

Hossain, M, M A Quasem, M M Akash and M A Jabbar. 1994. Differential impact of modern rice technology: the Bangladesh case. In: David, C., Otsuka, K. (Eds.), Modern Rice Technology and Income Distribution in Asia. Lynn Reinner Publishers, Boulder, CO.

Hossain, M, D Lewis, M LBoseand A Chowdhury. 2007. Rice research, technological progress, and poverty: The Bangladesh case. In: M Adato, and R Meinzen-Dick (Eds.), Agricultural Research, Livelihoods and Poverty: Studies of Economic and Social Impacts in Six Countries. Baltimore: Johns Hopkins University Press.

Imbens, G. 2004 'Nonparametric estimation of average treatment effects under exogeneity: A review.' The Review of Economics and Statistics, Vol. 86, pp. 4-29.
Islam, M A. 2018. "Impact of Modern Rice Varieties Adoption on Farmers' Well-Being (Livelihood) in Rural Bangladesh."Bangladesh Journal of Agricultural Economics, 38(1\&2), pp. 35-54.

Just, R E, and D Zilberman. 1988. "The effects of agricultural development policies on income distribution and technological change in agriculture", Journal of Development Economics, 28(2): 193-216.

Khonje, M, J Manda, A D Alene and M Kassie. 2015. "Analysis of adoption and impacts of Modern maize varieties in Eastern Zambia." World Development, 66: 695-706.

Mendola, M. 2007. “Agricultural technology adoption and poverty reduction: a propensity-score matching analysis for rural Bangladesh." Food Policy, 32(3): 372-393.

Meyer, B D, W K Viscusi, and D L Durbin.1995. Workers' compensation and injury duration: Evidence from a natural experiment. American Economic Review 85: 322-340.

MOA. 2019. Annual Report, Ministry of Agriculture, Govt. of the Peoples Republic of Bangladesh, Dhaka, Bangladesh.

Mora, R, and I Reggio. 2012. Treatment effect identification using alternative parallel assumptions. Working Paper 12-33, Universidad Carlos III de Madrid

Pingali, P L. 2012. Green revolution: impacts, limits, and the path ahead, Proceedings of the National Academy of Sciences of the USA, 109(31): 12302 12308.

Rabalino, J, and A Pfaff. 2013. 'Eco-payments and Deforestation in Costa Rica: A Nationwide Analysis of PSA's Initial Years', Land Economics, Vol.89(3), pp. 432-448.

Villa, J M. 2016. Diff: Simplifying the estimation of difference-in-differences treatment effects, The Stata Journal, 16(1), pp. 52-71.

Walker, T S. 2000. Reasonable expectations on the prospects for determining the impact of agricultural research on poverty in ex-post case studies. Food Policy, 25: 515-530.

Winters, P, A de Janvry, E Saudolet, and K Stamoulis. 1998. 'The role of agriculture in economic development: visible and invisible surplus transfers.' Journal of Development Studies, 345: 7197.

World Bank Group (WBG). 2016. Global monitoring report 2015/2016: Development goals in an era of demographic change. Washington, DC: World Bank, 2016/09/21.

Wu, H, S Ding, S Pandey and D Tao. 2010. Assessing the impact of agricultural technology adoption on farmers' well-being using propensity-score matching analysis in rural China, Asian Economic Journal, 24(2):141-166. 
